\title{
Influence of the electrochemical properties of vanadium oxides on specific capacitance by molybdenum doping
}

\author{
YUTING HUANG ${ }^{1,2}$ and YIFU ZHANG ${ }^{1, *} \mathbb{D}$ \\ ${ }^{1}$ School of Chemistry, Dalian University of Technology, Dalian 116024, People's Republic of China \\ ${ }^{2}$ Department of Chemical Engineering, Carnegie Mellon University, Pittsburgh, PA 15213, USA \\ *Author for correspondence (yfzhang@dlut.edu.cn)
}

MS received 21 August 2017; accepted 19 April 2018; published online 2 February 2019

\begin{abstract}
Molybdenum (Mo)-doped vanadium dioxide $\left(\mathrm{VO}_{2}(\mathrm{~B})\right)$ nanobelts were successfully synthesized using commercial vanadium pentoxide $\left(\mathrm{V}_{2} \mathrm{O}_{5}\right)$ as the starting material and ammonium molybdate as the dopant by a simple hydrothermal route. Then, Mo-doped $\mathrm{VO}_{2}(\mathrm{~B})$ nanobelts were transformed to Mo-doped $\mathrm{V}_{2} \mathrm{O}_{5}$ nanobelts by calcination at $400^{\circ} \mathrm{C}$ under an air atmosphere. The samples were characterized by X-ray powder diffraction, energy-dispersive X-ray spectrometer, elemental mapping, X-ray photoelectron spectroscopy, X-ray fluorescence and transmission electron microscopy techniques. The results showed that Mo-doped $\mathrm{VO}_{2}(\mathrm{~B})$ and $\mathrm{V}_{2} \mathrm{O}_{5}$ solid solution with high purity were obtained. The electrochemical properties of Mo-doped $\mathrm{VO}_{2}(\mathrm{~B})$ and $\mathrm{V}_{2} \mathrm{O}_{5}$ nanobelts as supercapacitor electrodes were measured using cyclic voltammetry (CV) and galvanostatic charge-discharge (GCD). The specific capacitance of $\mathrm{VO}_{2}(\mathrm{~B})$ nanobelts slightly declines with Mo doping, however, the specific capacitance of $\mathrm{V}_{2} \mathrm{O}_{5}$ nanobelts greatly improves with Mo doping. Mo-doped $\mathrm{V}_{2} \mathrm{O}_{5}$ nanobelts exhibit the specific capacitance as high as $526 \mathrm{~F} \mathrm{~g}^{-1}$ at the current density of $1 \mathrm{~A} \mathrm{~g}^{-1}$. Both $\mathrm{CV}$ and GCD curves show that they have good rate capability and retain $464,380,324$ and $273 \mathrm{~F} \mathrm{~g}^{-1}$ even at a high-current density of 2, 5, 10 and $20 \mathrm{~A} \mathrm{~g}^{-1}$, respectively. It turns out that Mo-doped $\mathrm{V}_{2} \mathrm{O}_{5}$ nanobelts are ideal materials for supercapacitor electrodes in the present work.
\end{abstract}

Keywords. Mo-doped $\mathrm{VO}_{2}(\mathrm{~B})$ nanobelts; Mo-doped $\mathrm{V}_{2} \mathrm{O}_{5}$ nanobelts; chemical synthesis; electrochemical properties; specific capacitance.

\section{Introduction}

Because of the advantages of high-power density, superior rate capability, excellent cycling life and environmentally friendly, supercapacitors (SCs) have grown into novel efficient energy storage devices, which have drawn great attention. SCs have tremendous potential in application in the fields of energy sources, communication, aerospace industry, electronic devices, etc. [1-7]. In order to expand the depth and scope of their application, the energy density is supposed to be improved. In particular, the exceptional electrode material is the key factor. According to the differences in storage mechanisms, SCs can be classified into two types: electrochemical double layer capacitors (EDLCs) and pseudocapacitors (PCs). EDLCs physically store charges by reversible ion adsorption at the electrode-electrolyte interface, while PCs mainly chemically store the charges by redox reactions. Typically, electrode materials for EDLCs are composed of high surface area carbon-based materials, while electrode materials for PCs are composed of conductive polymers and transition metal oxides/hydroxides/sulphides $[1,8]$. Electrochemical capacitors (ECs) based on transition metal oxides/hydroxides/sulphides exhibit much higher specific capacitance than conventional carbon materials and better electrochemical stability than conducting polymers
$[9,10]$. Thus, it is urgent to discover inexpensive electrode materials made from transition metal oxides/hydroxides/sulphides with excellent performance, which becomes the focus in the research of SCs.

In the previous reports, some kinds of transition metal oxides/hydroxides/sulphides were already studied, including $\mathrm{RuO}_{2}, \mathrm{NiO}, \mathrm{CuO}, \mathrm{MnO}_{2}, \mathrm{Co}_{3} \mathrm{O}_{4}$, etc., however, their relatively high price or low conductivity hampered further application [8,11-14]. Under these circumstances, vanadium oxides $\left(\mathrm{VO}_{x}\right)$ have drawn increasingly greater interest due to their advantages including low lost, stable chemical and physical properties, high specific capacity and energy density, etc. $[6,15-29]$. The multiple valence states $\left(\mathrm{V}^{5+}, \mathrm{V}^{4+}\right.$, $\mathrm{V}^{3+}$ and $\mathrm{V}^{2+}$ ) of vanadium can make it possible to form different kinds of oxides. Meanwhile, the unique layered structure favours the diffusion of metal ions or organic groups. Thus, $\mathrm{VO}_{x}$ have been considered as promising electrode materials, on which plenty of research has been carried out to improve their electrochemical performance.

On the one hand, as the morphology and crystal structure play a significant role in influencing the capacitive properties of electrode materials, $\mathrm{VO}_{x}$ with novel structures have been prepared and studied [16,30,31]. The contact area between the electrode materials and electrolyte can be promoted via adjusting the morphology of electrode 
materials. As members of the family of $\mathrm{VO}_{x}$, vanadium dioxide $\mathrm{VO}_{2}(\mathrm{~B})$ and vanadium pentoxide $\left(\mathrm{V}_{2} \mathrm{O}_{5}\right)$ are considered to be great candidates for efficient electrode materials which have potential in development and application. In recent years, nano-structured $\mathrm{VO}_{2}(\mathrm{~B})$ and $\mathrm{V}_{2} \mathrm{O}_{5}$ with different morphologies [16,19,30-36] including hollow spheres, microspheres, thin films, nanofibres, nanowires, nanoribbons, nanotubes, nanorods, nanoporous structures, nanosheets constructing 3D architectures, layer-by-layer structures, interconnected $\mathrm{V}_{2} \mathrm{O}_{5}$ nanoporous networks, etc. have been synthesized by different approaches and their activity has been tested for SC applications. On the other hand, to improve the structure stability of electrode materials during the insertion and extraction of the metal ions in the electrolyte, materials with multi-composition based on $\mathrm{VO}_{x}$ were prepared and studied, including $\mathrm{VO}_{x} /$ carbon-based materials and doped $\mathrm{VO}_{x}$. The former $\mathrm{VO}_{x} /$ carbon-based materials have been extensively studied in recent years [17,37-39]. However, doped $\mathrm{VO}_{x}$ materials used in the improvement of the electrochemical properties of $\mathrm{VO}_{x}$ have been comparatively less reported. Jeyalakshmi et al [40] reported Ni-doped $\beta-\mathrm{V}_{2} \mathrm{O}_{5}$ thin films with $5 \mathrm{wt} \%$ of $\mathrm{Ni}$ exhibiting the specific capacitance of $417 \mathrm{~F} \mathrm{~g}^{-1}$ at a scan rate of $5 \mathrm{mV} \mathrm{s}^{-1}$. Our group reported $\mathrm{W}$-doped $\mathrm{VO}_{2}$ showing the specific capacitance of $253 \mathrm{~F} \mathrm{~g}^{-1}$ at the current density of $1 \mathrm{~A} \mathrm{~g}^{-1}$ [20]. Except these, there has been no literature reports about doped $\mathrm{VO}_{x}$ materials used to improve their specific capacitance, to the best of our knowledge [41]. Therefore, to promote the specific capacitance of $\mathrm{VO}_{x}$ electrodes with additives is meaningful and challenging for materials researchers.

Herein, we first prepared Mo-doped $\mathrm{VO}_{2}(\mathrm{~B})$ and $\mathrm{V}_{2} \mathrm{O}_{5}$ nanomaterials to improve their specific capacitance of $\mathrm{VO}_{x}$. It was found that $2 \%$ Mo-doped $\mathrm{V}_{2} \mathrm{O}_{5}$ nanomaterials exhibited the best specific capacitance as high as $526 \mathrm{~F} \mathrm{~g}^{-1}$ at the current density of $1 \mathrm{~A} \mathrm{~g}^{-1}$.

\section{Experimental}

\subsection{Materials}

Commercial $\mathrm{V}_{2} \mathrm{O}_{5}$, hydrogen peroxide $\left(\mathrm{H}_{2} \mathrm{O}_{2}, 30\right.$ wt $\left.\%\right)$, ammonium molybdate and ethanol (EtOH) of analytical grade were purchased from Sinopharm Chemical Reagent Co., Ltd. and used without any further purification.

\subsection{Synthesis of Mo-doped $\mathrm{VO}_{2}(B)$ nanomaterials}

Synthesis of Mo-doped $\mathrm{VO}_{2}(\mathrm{~B})$ nanomaterials was carried out according to our previous report [42] with slight modification. In a typical procedure, $0.455 \mathrm{~g}$ of commercial $\mathrm{V}_{2} \mathrm{O}_{5}$ powder was dispersed into $28 \mathrm{ml}$ of deionized water in a $100 \mathrm{ml}$ beaker with magnetic stirring at room temperature for $10 \mathrm{~min}$. Then, $2 \mathrm{ml}$ of $\mathrm{H}_{2} \mathrm{O}_{2}(30 \mathrm{wt} \%)$ and $5 \mathrm{ml}$ of $\mathrm{EtOH}$ were successively added to the above mixture. After vigorously stirring for $30 \mathrm{~min}$ at room temperature, an amount of ammonium molybdate $[n(\mathrm{Mo}) / n(\mathrm{~V}+\mathrm{Mo}) \times 100 \%=0,1.0$,
2.0, 4.0, 8.0\%; the corresponding content is $0,0.083,0.173$, $0.348,0.698 \mathrm{~g}]$ was added into the above solution. After another $0.5 \mathrm{~h}$ of stirring, the mixture was transferred into a $50 \mathrm{ml}$ Teflon lined stainless steel autoclave, sealed and maintained at $180^{\circ} \mathrm{C}$ for $48 \mathrm{~h}$. After the reaction, the products were filtered off, washed with $\mathrm{H}_{2} \mathrm{O}$ and $\mathrm{EtOH}$ several times to remove any possible residue, and dried in a vacuum at $75^{\circ} \mathrm{C}$ for $12 \mathrm{~h}$.

\subsection{Synthesis of Mo-doped $\mathrm{V}_{2} \mathrm{O}_{5}$ nanomaterials}

To obtain Mo-doped $\mathrm{V}_{2} \mathrm{O}_{5}$ nanomaterials, $0.2 \mathrm{~g}$ of the above Mo-doped $\mathrm{VO}_{2}(\mathrm{~B})$ nanomaterials were placed in a crucible and heated using a muffle furnace at a $5^{\circ} \mathrm{C} \mathrm{min}^{-1}$ heating rate under an air atmosphere at $400^{\circ} \mathrm{C}$ for $4 \mathrm{~h}$, and then cooled to room temperature naturally.

\subsection{Materials characterization}

The phase and composition of the products were identified by X-ray powder diffraction (XRD, Panalytical X'Pert powder diffractometer at $40 \mathrm{kV}$ and $40 \mathrm{~mA}$ with Ni-filtered $\mathrm{Cu} \mathrm{K} \alpha$ radiation). The chemical composition of the asobtained samples was revealed by the use of an energydispersive X-ray spectrometer (EDS) and elemental mapping attached to a scanning electron microscope (SEM, QUANTA450). X-ray photoelectron spectroscopy (XPS) was used to investigate the composition of the products and confirm the oxidation state of vanadium preformed on an ESCALAB250Xi, Thermo Fisher Scientific. The compositions of the doped materials were tested by X-ray fluorescence (XRF, XRF-1800, Shimadzu, Japan). The morphology and dimensions of the products were observed by transmission electron microscopy (TEM, FEI Tecnai F30, FEI). The samples were dispersed in absolute EtOH with ultrasonication before TEM characterization.

\subsection{Electrochemical characterization}

Electrochemical tests were performed using a three-electrode cell, in which Ni-grid and saturated calomel electrode (SCE) were used as the counter and the reference electrodes, respectively. The working electrodes were composed of $80 \mathrm{wt} \%$ of active material (Mo-doped $\mathrm{VO}_{x}$ ), $10 \mathrm{wt} \%$ of carbon black and $10 \mathrm{wt} \%$ of polyvinylidene difluoride (PVDF). $\mathrm{N}$-Methyl-2pyrrolidone (NMP) was used as a solvent. The mixed slurries were coated onto $\mathrm{Ni}$ foils and heated at $80^{\circ} \mathrm{C}$ overnight to remove the organic solvent. Then, these foils were pressed onto Ni-grids at a pressure of $10 \mathrm{MPa}$. Cyclic voltammetry (CV) and galvanostatic charge-discharge (GCD) were used to obtain the electrochemical characteristics. The electrolyte was $1 \mathrm{~mol} \mathrm{l}^{-1} \mathrm{Na}_{2} \mathrm{SO}_{4}$ aqueous solution in the electrochemical tests of Mo-doped $\mathrm{VO}_{2}(\mathrm{~B})$ nanomaterials. $\mathrm{CV}$ data were collected between -0.7 and $1.0 \mathrm{~V}$ and GCD tests were performed in the potential range of -0.7 to $1.0 \mathrm{~V}$ at a current density of $1 \mathrm{~A} \mathrm{~g}^{-1}$. The electrolyte was $1 \mathrm{~mol} \mathrm{l}^{-1}$ 

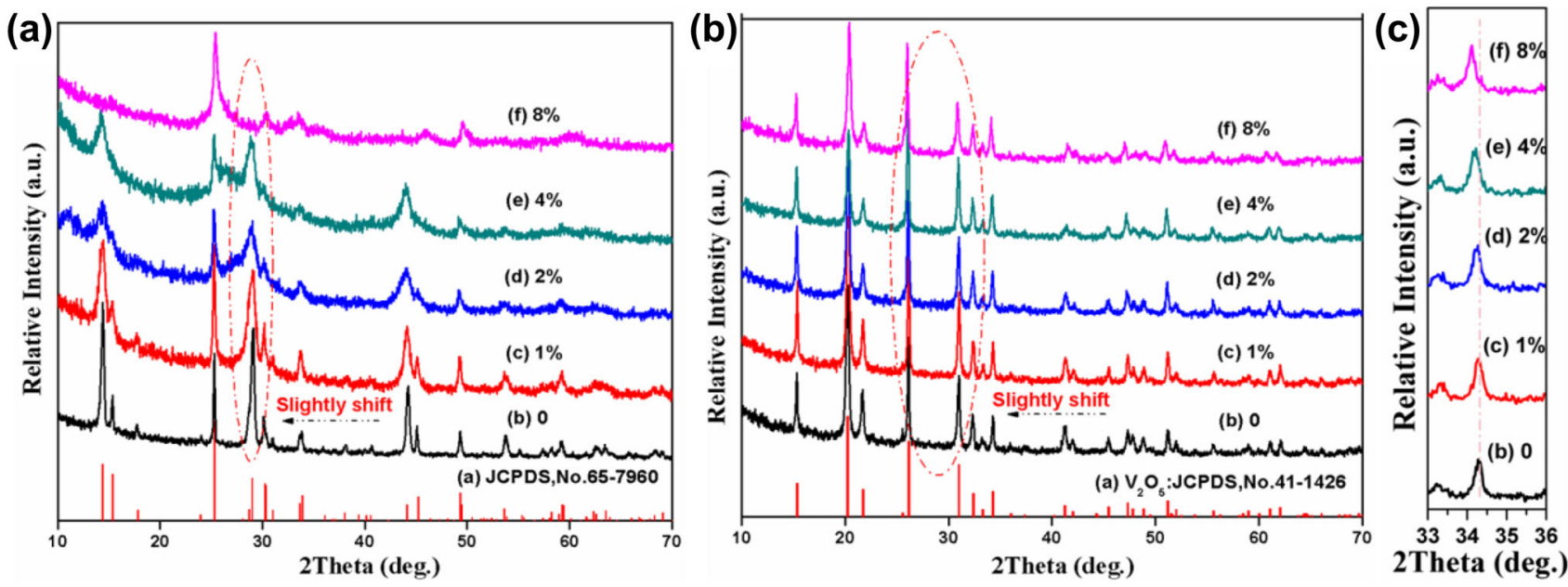

Figure 1. XRD patterns of Mo-doped $\mathrm{VO}_{x}$ with different Mo-doped fractions: (a) Mo-doped $\mathrm{VO}_{2}(\mathrm{~B})$ nanobelts; $\left(\mathbf{b}\right.$, c) Mo-doped $\mathrm{V}_{2} \mathrm{O}_{5}$ nanobelts.

$\mathrm{LiNO}_{3}$ solution in the electrochemical tests of Mo-doped $\mathrm{V}_{2} \mathrm{O}_{5}$ nanomaterials. $\mathrm{CV}$ data were collected between -0.5 and $0.6 \mathrm{~V}$ at different scan rates $\left(2-100 \mathrm{mV} \mathrm{s}^{-1}\right)$ and GCD tests were performed in the potential range of -0.5 to $0.6 \mathrm{~V}$ at a current density of $0.2-20 \mathrm{~A} \mathrm{~g}^{-1}$.

The average specific capacitance obtained from $\mathrm{CV}$ was calculated according to equation (1):

$$
C_{\mathrm{v}}=\frac{S}{2 m v \cdot \Delta V}
$$

where $C_{\mathrm{v}}\left(\mathrm{F} \mathrm{g}^{-1}\right)$ is the specific capacitance, $S$ is the area under the $\mathrm{CV}$ curve, $m(\mathrm{~g})$ is the mass of active material within the electrode, $v\left(\mathrm{mV} \mathrm{s}^{-1}\right)$ is the scan rate and $\Delta V(\mathrm{~V})$ represents the potential drop during the discharge process. The specific capacitance $\left(C_{\mathrm{p}}, \mathrm{F} \mathrm{g}^{-1}\right)$ of the active material in the electrode determined using the charge-discharge curves can be calculated using equation (2):

$$
C_{\mathrm{p}}=\frac{I \cdot \Delta t}{m \cdot \Delta V}
$$

where $I(\mathrm{~A})$ is the discharge current and $\Delta t(\mathrm{~s})$ is the discharge time. The energy density $E\left(\mathrm{~W} \mathrm{~h} \mathrm{~kg}^{-1}\right)$ of the active material in the electrode can be calculated using equation (3):

$$
E=\frac{1}{2} C \cdot(\Delta V)^{2}
$$

The power density $P\left(\mathrm{~W} \mathrm{~kg}^{-1}\right)$ can be calculated from the energy density $E$ and the discharge time $\Delta t$ according to equation (4):

$$
P=\frac{E}{\Delta t}
$$

\section{Results and discussion}

\subsection{Characterization of Mo-doped $V O_{x}$ nanomaterials}

The crystal structure and phase purity of the prepared samples were characterized by XRD, as shown in figure 1 . Figure 1a depicts the XRD patterns of the as-prepared $\mathrm{VO}_{2}(\mathrm{~B})$ with different Mo-doped fractions obtained by the direct hydrothermal route. It could be found that Mo doping had influence on the crystal structure and phase purity of $\mathrm{VO}_{2}(\mathrm{~B})$. Without Mo doping, well crystalline $\mathrm{VO}_{2}$ (B) (JCPDS no. 657960) [43] was obtained and no other $\mathrm{VO}_{x}$ were detected. With the increase of the concentration of Mo-doped fractions, the crystallization of $\mathrm{VO}_{2}(\mathrm{~B})$ decreased compared with the XRD patterns of undoped $\mathrm{VO}_{2}(\mathrm{~B})$ as shown in figure 1a. Meanwhile, it could be observed that some peaks of doped $\mathrm{VO}_{2}$ (B) shifted slightly towards lower $2 \theta$ value. Typically, the peak located at $27.88^{\circ}$ shifted towards small reflection angle with increasing Mo-doped fractions, suggesting that the adjacent interplanar distance ( $d$-value) slightly increased. It's well known that the ionic radius of the Mo atom is larger than that of the $\mathrm{V}$ atom, so the slight increase in the $d$-value is attributed to Mo atoms substituting $\mathrm{V}$ atoms in the $\mathrm{VO}_{2}$ lattice, resulting in the peak shift towards low $2 \theta$ angle. When the concentration of Mo-doped fractions reached $8 \%$, although the phase $\mathrm{VO}_{2}(\mathrm{~B})$ still remained, the peak at $14.4^{\circ}$ and the peak at $44.1^{\circ}$ disappeared. The reason could be that the growth of $\mathrm{VO}_{2}$ (B) had been stunted due to the high concentration of dopants in the system [44]. After the calcination at $400^{\circ} \mathrm{C}$ under the air atmosphere, Mo-doped $\mathrm{VO}_{2}$ (B) was converted to Mo-doped $\mathrm{V}_{2} \mathrm{O}_{5}$ (JCPDS no. 411426) [45], as shown in figure 1b. It could also be observed that some peaks of doped $\mathrm{V}_{2} \mathrm{O}_{5}$ shifted slightly towards lower $2 \theta$ value, which was consistent with the result of Mo-doped $\mathrm{VO}_{2}(\mathrm{~B})$. 

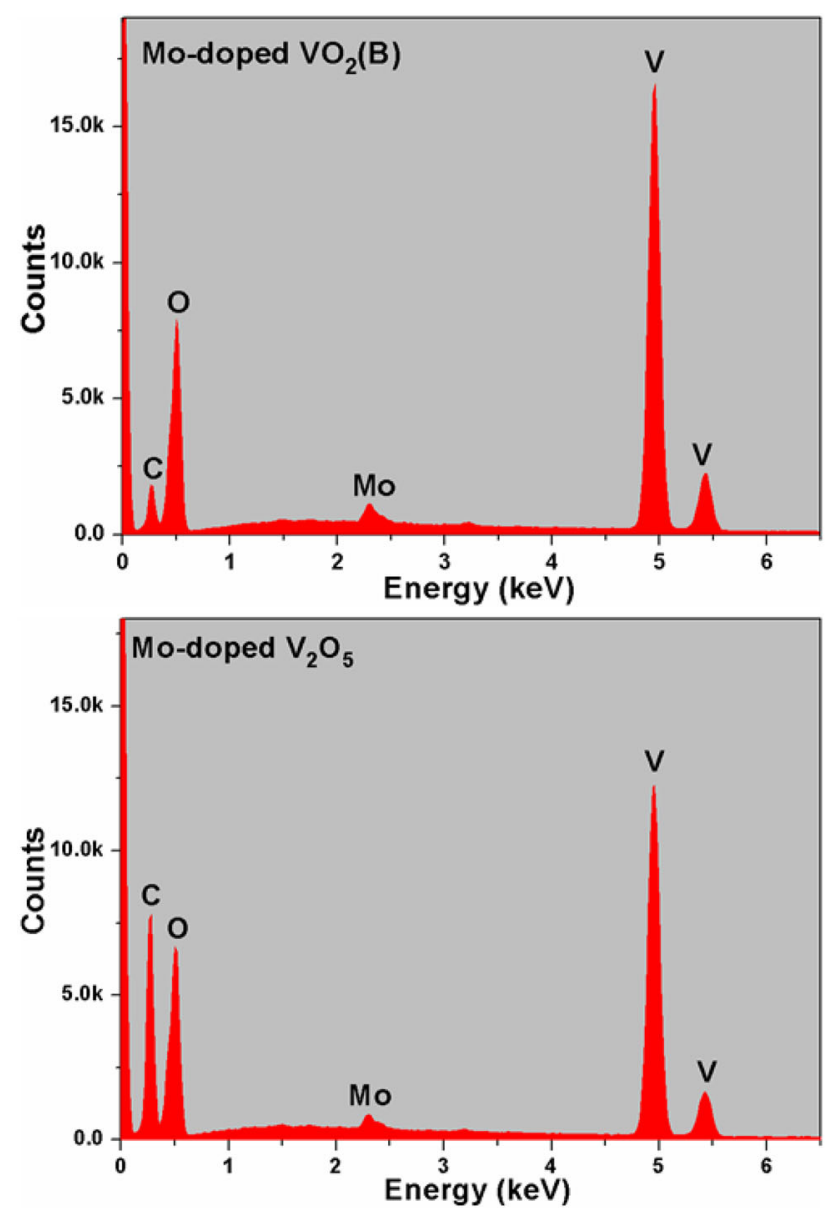

Figure 2. EDS spectra of $2 \%$ Mo-doped $\mathrm{VO}_{2}(\mathrm{~B})$ nanobelts and $2 \%$ Mo-doped $\mathrm{V}_{2} \mathrm{O}_{5}$ nanobelts.

Further information about the composition of the as-obtained Mo-doped $\mathrm{VO}_{x}$ was characterized by EDS, elemental mapping and XPS and we chose the samples with the concentration of $2 \%$ Mo. Figure 2 shows the EDS spectra of Mo-doped $\mathrm{VO}_{2}(\mathrm{~B})$ and Mo-doped $\mathrm{V}_{2} \mathrm{O}_{5}$. Both of them revealed that the samples consisted of $\mathrm{V}, \mathrm{O}$ and Mo elements. It is noted that $\mathrm{C}$ was from the conducting resin which was used to paste and fix the sample during the test. Figure 3 depicts elemental mapping images of Mo-doped $\mathrm{VO}_{2}(\mathrm{~B})$ and Mo-doped $\mathrm{V}_{2} \mathrm{O}_{5}$, and also reveals that these two samples consisted of $\mathrm{V}, \mathrm{O}$ and Mo elements. Furthermore, these elements have homogeneous distribution in the field of vision, which corresponded to the XRD observation.

Important information about the surface molecular and electronic structure of the as-obtained sample, as well as the chemical element valence, was provided by XPS. The binding energies obtained from the XPS analysis were corrected for specimen charging by referencing $\mathrm{C}_{1 \mathrm{~s}}$ to $284.81 \mathrm{eV}$ [46]. Figure 4 shows the XPS spectra of the as-obtained Mo-doped $\mathrm{VO}_{2}$ (B) and Mo-doped $\mathrm{V}_{2} \mathrm{O}_{5}$. The survey spectra (figure $4 \mathrm{a}$ and d) indicated that there were only three elements $\mathrm{V}, \mathrm{O}$ and Mo in the spectra of these two samples, in agreement with the observation of EDS and elemental mapping. As for Mo-doped $\mathrm{VO}_{2}(\mathrm{~B})$, binding energy at $530.3 \mathrm{eV}$ (figure 4b) was assigned to the $\mathrm{O}_{1 \mathrm{~s}}$ peak. The core-level spectrum of $\mathrm{V}_{2 \mathrm{p}}$ peak (figure $4 \mathrm{~b}$ ) split off into two peaks, including $\mathrm{V}_{2 \mathrm{p} 1 / 2}$ with a binding energy of $524.3 \mathrm{eV}$ and $V_{2 \mathrm{p} 3 / 2}$ with a binding energy of $516.9 \mathrm{eV}$, which were the characteristics of vanadium in the +4 oxidation state $[47,48]$, in agreement with XRD observation. The above results were very consistent with the model of Mo-doped $\mathrm{VO}_{2}(\mathrm{~B})$ in the previous reports [47-50]. The value for the $\mathrm{V}_{2 \mathrm{p} 3 / 2}$ peak was slightly higher than that for pure $\mathrm{VO}_{2}$ powder $[47,48]$, but was in agreement with the reports of $\mathrm{W}$ doped $\mathrm{VO}_{2}$ [44,51], suggesting that the binding energy of $\mathrm{V}_{2 \mathrm{p} 3 / 2}$ increased slightly after Mo doping. As for Mo-doped $\mathrm{V}_{2} \mathrm{O}_{5}$, the binding energy of the $\mathrm{O}_{1 \mathrm{~s}}$ peak was located at $530.5 \mathrm{eV}$ (figure 4e). The $\mathrm{V}_{2 \mathrm{p}}$ peak (figure 4e) consisted of $\mathrm{V}_{2 \mathrm{p} 1 / 2}$ with a binding energy of $525.1 \mathrm{eV}$ and $\mathrm{V}_{2 \mathrm{p} 3 / 2}$ with a binding energy of $517.5 \mathrm{eV}$, corresponding to vanadium in the +5 oxidation state $[47,48]$. This result is well in agreement with XRD observation. Figure $4 \mathrm{c}$ and $\mathrm{f}$, respectively, describe the core-level spectra of $\mathrm{Mo}_{3 \mathrm{~d}}$ peak of these two samples, which split off into two peaks $\mathrm{Mo}_{3 \mathrm{~d} 3 / 2}$ and $\mathrm{Mo}_{3 \mathrm{~d} 5 / 2}$. The binding energies of $\mathrm{Mo}_{3 \mathrm{~d} 3 / 2}$ and $\mathrm{Mo}_{3 \mathrm{~d} 5 / 2}$ peaks were centred at 235.7 and $232.5 \mathrm{eV}$ in Mo-doped $\mathrm{VO}_{2}(\mathrm{~B})$ (figure 4c) and 235.9 and $232.7 \mathrm{eV}$ in Mo-doped $\mathrm{V}_{2} \mathrm{O}_{5}$ (figure $4 \mathrm{c}$ ). According to the standard binding energy, the existing form of molybdenum in both samples was $\mathrm{Mo}^{6+}$ [48]. Therefore, based on the analyses of XRD, EDS, elemental mapping and XPS, Modoped $\mathrm{VO}_{2}(\mathrm{~B})$ and Mo-doped $\mathrm{V}_{2} \mathrm{O}_{5}$ solid solutions with high purity were successfully synthesized.

Table 1 typically lists the composition of $2 \%$ Mo-doped $\mathrm{VO}_{2}(\mathrm{~B})$ and $2 \%$ Mo-doped $\mathrm{V}_{2} \mathrm{O}_{5}$ characterized by XRF. The weight contents of $\mathrm{O}, \mathrm{V}$ and $\mathrm{W}$ elements were $38.07,59.73$ and $2.20 \mathrm{wt} \%$ of Mo-doped $\mathrm{VO}_{2}(\mathrm{~B})$ and 43.51, 54.57 and $1.92 \mathrm{wt} \%$ of Mo-doped $\mathrm{V}_{2} \mathrm{O}_{5}$, respectively, revealing that their atomic ratio was 1.9926:0.9808:0.0192 $(n(\mathrm{Mo}) / n(\mathrm{~V}+$ $\mathrm{Mo}) \times 100 \%=1.92 \%)$ and 2.4948:0.9816:0.0184 $(n(\mathrm{Mo}) /$ $n(\mathrm{~V}+\mathrm{Mo}) \times 100 \%=1.84 \%)$. These results revealed that the real contents of Mo in final products were slightly lower than its corresponding nominal contents. The reason was that the dopants and $\mathrm{VO}_{x}$ had different speeds of co-precipitation or the dopants impede the growth of $\mathrm{VO}_{x}$ [46]. To be convenient for readers, we used the data of the Mo atomic percent in feed in this study.

The typical TEM images of the samples are shown in figure 5. Without any additives, it could be observed from figure $5 \mathrm{a}$ and $\mathrm{b}$ that the Mo-doped $\mathrm{VO}_{2}(\mathrm{~B})$ displayed the belt-like morphology, thus $\mathrm{VO}_{2}(\mathrm{~B})$ nanomaterials were synthesized in agreement with the previous report [42]. The average diameter was in the range of $50-100 \mathrm{~nm}$ and the length was up to $1 \mu \mathrm{m}$. With $2 \%$ Mo dopant, as shown in figure $5 \mathrm{c}$ and d, the morphology of Mo-doped $\mathrm{VO}_{2}(\mathrm{~B})$ was little influenced by the Mo doping. After the heat treatment at $400^{\circ} \mathrm{C}$, the morphology of Mo-doped $\mathrm{V}_{2} \mathrm{O}_{5}$ was similar to Mo-doped $\mathrm{VO}_{2}(\mathrm{~B})$. It could be observed from figure $5 \mathrm{e}$ and $\mathrm{f}$ that Mo-doped $\mathrm{V}_{2} \mathrm{O}_{5}$ displayed a belt-like morphology. However, the edge and surface of Mo-doped $\mathrm{V}_{2} \mathrm{O}_{5}$ nanomaterials became broken and girdle 


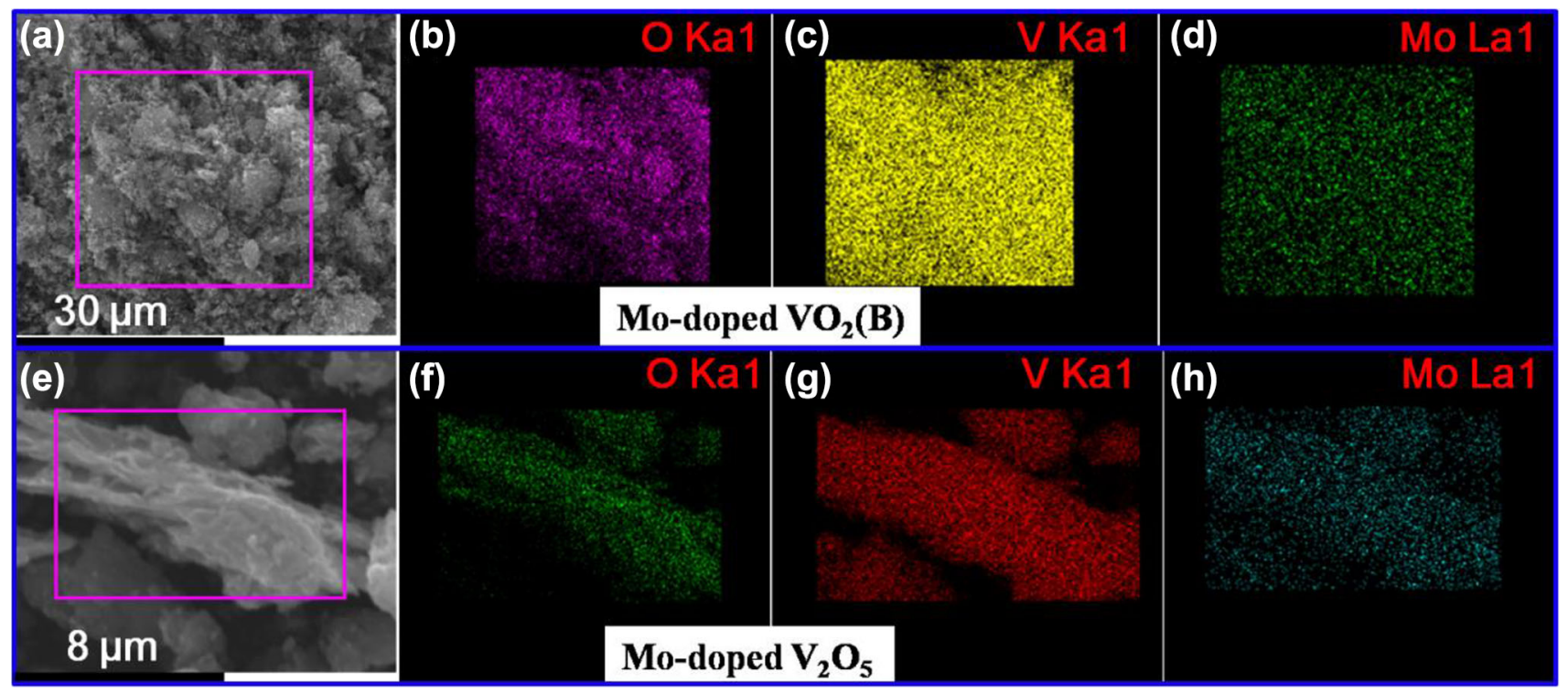

Figure 3. SEM images and their corresponding elemental mapping images of (a-d) $2 \%$ Mo-doped $\mathrm{VO}_{2}(\mathrm{~B})$ nanobelts and (e-h) $2 \%$ Mo-doped $\mathrm{V}_{2} \mathrm{O}_{5}$ nanobelts.
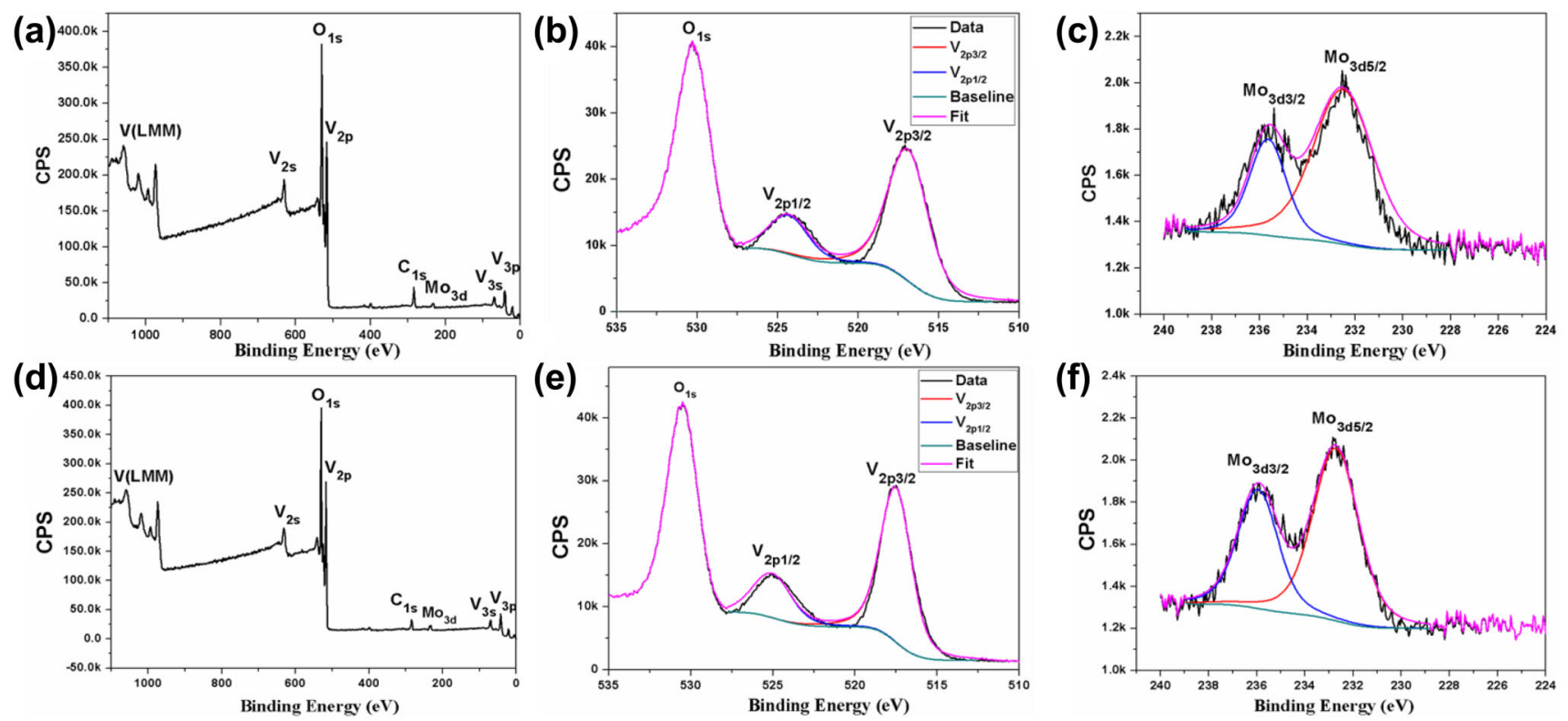

Figure 4. XPS spectra of $2 \%$ Mo-doped (a-c) $\mathrm{VO}_{2}(\mathrm{~B})$ and $(\mathbf{d}-\mathbf{f}) \mathrm{V}_{2} \mathrm{O}_{5}$ nanobelts: (a, d) survey spectrum; (b, e) $\mathrm{O}_{1 \mathrm{~s}}$ and $\mathrm{V}_{2} \mathrm{p}$ peaks; (c, f) Mo3d peak.

Table 1. The composition of the doped $\mathrm{VO}_{x}$ by the XRF test.

\begin{tabular}{lcccc}
\hline Sample & $\mathrm{O}, \mathrm{wt} \%$ & $\mathrm{~V}, \mathrm{wt} \%$ & Mo, wt\% & O:V:Mo, atomic ratio \\
\hline Mo-doped $\mathrm{VO}_{2}(\mathrm{~B})$ & 38.07 & 59.73 & 2.20 & $1.9926: 0.9808: 0.0192$ \\
Mo-doped $\mathrm{V}_{2} \mathrm{O}_{5}$ & 43.51 & 54.57 & 1.92 & $2.4948: 0.9816: 0.0184$ \\
\hline
\end{tabular}

roughness to some extent, which was owing to the growth, transformation or aggregation by surface and boundary diffusion during the calcination process. The above characteristic of the as-obtained $\mathrm{V}_{2} \mathrm{O}_{5}$ nanomaterials suggested that they had high capacitance to be used as SC electrodes [31]. Furthermore, the microstructure of the $\mathrm{VO}_{x}$ nanobelts was 

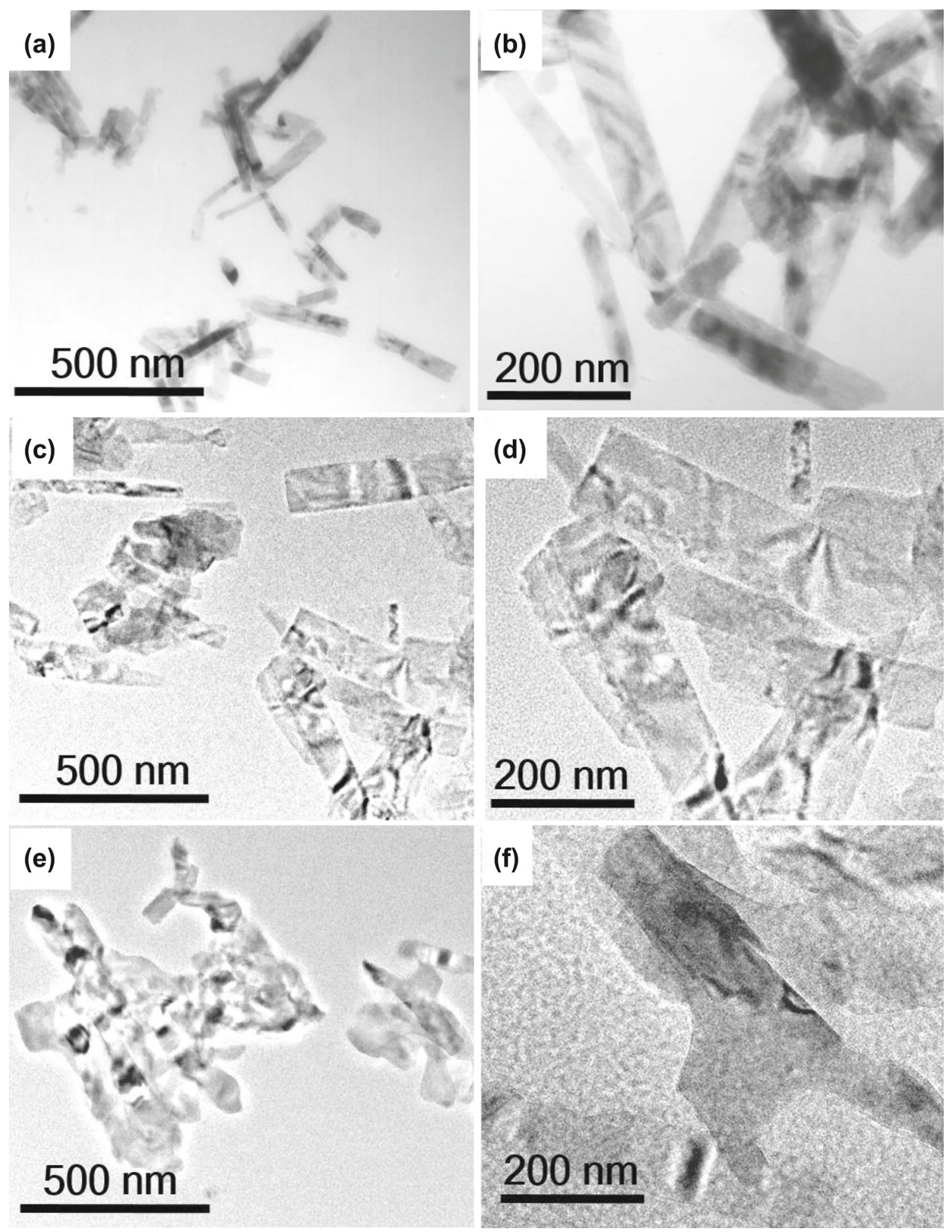

Figure 5. TEM images of the samples: $(\mathbf{a}, \mathbf{b}) \mathrm{VO}_{2}(\mathrm{~B}) ;(\mathbf{c}, \mathbf{d}) 2 \%$ Mo-doped $\mathrm{VO}_{2}(\mathrm{~B}) ;(\mathbf{e}, \mathbf{f}) 2 \%$ Mo-doped $\mathrm{V}_{2} \mathrm{O}_{5}$ nanomaterials.

studied by high-resolution transmission electron microscopy (HRTEM). As shown in figure 6a, the HRTEM image of Mo-doped $\mathrm{VO}_{2}(\mathrm{~B})$ revealed that the distance between the neighbouring planes was about $0.311 \mathrm{~nm}$. This value was consistent with that of the (002) plane of $\mathrm{VO}_{2}(\mathrm{~B})$, which was in agreement with the $d_{002}$ spacing in the XRD patterns (figure 1a). The HRTEM image (figure 6b) of Mo-doped $\mathrm{V}_{2} \mathrm{O}_{5}$ revealed that the distance between the neighbouring planes 

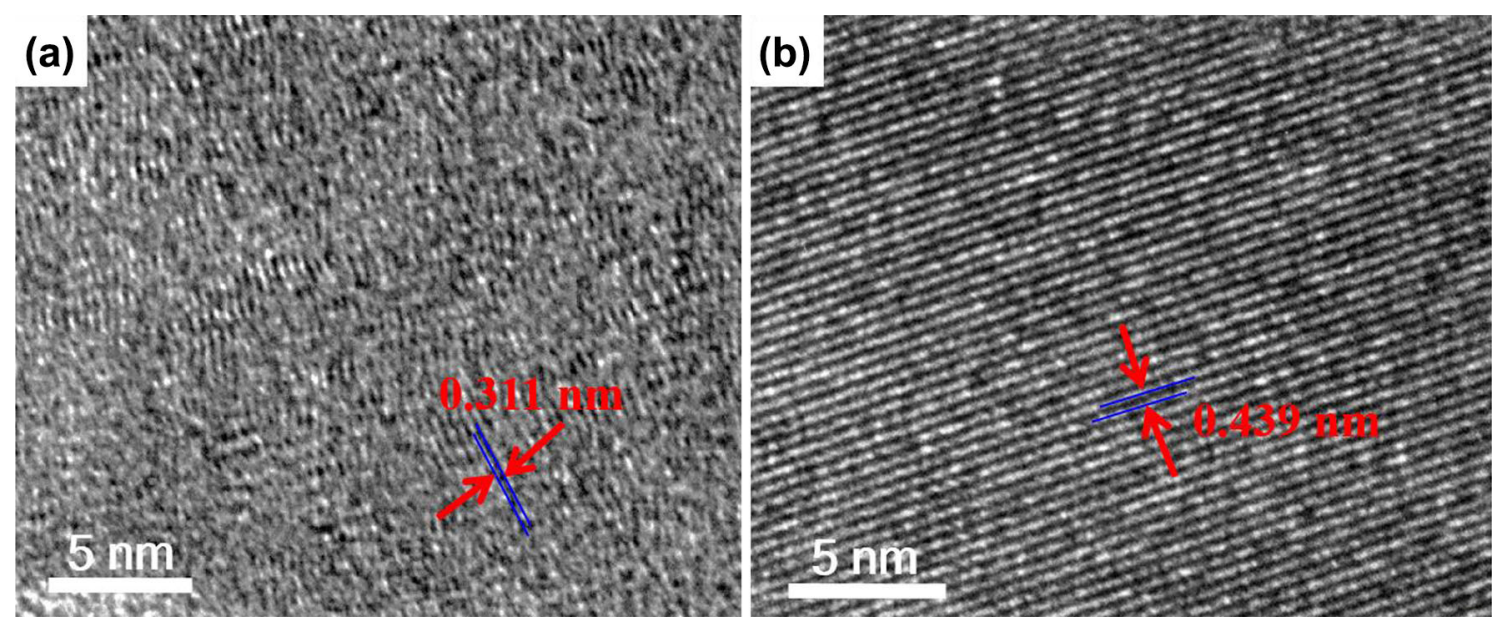

Figure 6. HRTEM images of the samples: (a) $2 \%$ Mo-doped $\mathrm{VO}_{2}$ (B) nanomaterials and (b) $2 \%$ Mo-doped $\mathrm{V}_{2} \mathrm{O}_{5}$ nanomaterials.

was about $0.439 \mathrm{~nm}$. This value was consistent with that of the (001) plane of $\mathrm{V}_{2} \mathrm{O}_{5}$, which was in agreement with the $d_{001}$ spacing in the XRD patterns (figure $1 b$ ).

\subsection{Electrochemical properties of Mo-doped $V O_{x}$ nanomaterials}

To exhibit the merits of the as-obtained Mo-doped $\mathrm{VO}_{x}$ nanomaterials, their electrochemical properties for SC electrodes were studied by the $\mathrm{CV}$ and GCD methods in a three-electrode cell. Figure 7a shows the $\mathrm{CV}$ curves of Mo-doped $\mathrm{VO}_{2}(\mathrm{~B})$ obtained with different concentrations of Mo fractions $(0$, 1, 2, 4 and 8\%). All curves had similar shapes and exhibited two pairs of redox peaks, indicating that all samples had pseudocapacitive behaviour. From the analyses of CV curves, the specific capacitances of Mo-doped $\mathrm{VO}_{2}(\mathrm{~B})$ nanomaterials prepared with the concentrations of Mo-doped fractions $(0,1,2,4$ and $8 \%)$ were, respectively, 227, 191, 200, 158 and $126 \mathrm{~F} \mathrm{~g}^{-1}$, indicating that Mo-doping is not beneficial for $\mathrm{VO}_{2}(\mathrm{~B})$ nanomaterials to improve their electrochemical performance and the values of pseudocapacitance were also obtained by GCD. Figure 7b shows their corresponding variations of potential $v s$. time for discharge curves recorded by the GCD test with a high-current density of $1 \mathrm{~A} \mathrm{~g}^{-1}$. It could be clearly observed that as the concentration of Mo-doped fractions increased, the specific capacitance of Mo-doped $\mathrm{VO}_{2}(\mathrm{~B})$ nanomaterials displayed a downwards trend in general. The specific capacitances of Mo-doped $\mathrm{VO}_{2}(\mathrm{~B})$ nanomaterials prepared with the concentrations of Mo-doped fractions ( 0 , $1,2,4$ and 8\%) are, respectively, 221, 190, 194, 155 and $121 \mathrm{~F} \mathrm{~g}^{-1}$, corresponding to $\mathrm{CV}$ observations. The specific capacitance of Mo-doped $\mathrm{VO}_{2}(\mathrm{~B})$, synthesized when the concentration of Mo-doped fractions was $2 \%$, was slightly higher than that of $1 \%$ doping. These results indicated that although Mo doping could not improve the energy storage capability of $\mathrm{VO}_{2}(\mathrm{~B})$ nanomaterials, a moderate amount of Mo doping may bring about some unique changes in the structure of $\mathrm{VO}_{2}(\mathrm{~B})$ nanomaterials, thus influencing their properties, which deserve further study. Owing to this reason, we transformed Mo-doped $\mathrm{VO}_{2}$ (B) to Mo-doped $\mathrm{V}_{2} \mathrm{O}_{5}$, and it was found that Mo-doped $\mathrm{V}_{2} \mathrm{O}_{5}$ could improve the specific capacitance of $\mathrm{V}_{2} \mathrm{O}_{5}$. Figure $7 \mathrm{c}$ shows the $\mathrm{CV}$ curves of Mo-doped $\mathrm{V}_{2} \mathrm{O}_{5}$ nanomaterials obtained with different concentrations of Mo fractions (0, 1, 2, 4 and 8\%). All curves had similar shapes and exhibited two pairs of redox peaks, indicating that all samples had pseudocapacitive behaviour. The specific capacitances of Mo-doped $\mathrm{V}_{2} \mathrm{O}_{5}$ nanomaterials prepared with concentrations of Mo fractions $(0,1,2,4$ and $8 \%)$ from the $\mathrm{CV}$ curves were, respectively, 450, 435, 521, 442 and $283 \mathrm{~F} \mathrm{~g}^{-1}$. Figure $7 \mathrm{~d}$ depicts their corresponding variations of potential $v s$. time for discharge curves recorded by the GCD test with a high-current density of $1 \mathrm{~A} \mathrm{~g} \mathrm{~g}^{-1}$. The relatively symmetrical potential-time curves could be observed. Each curve had two distinct potential plateaus which was well consistent with the redox peaks in the $\mathrm{CV}$ curves depicted in figure $7 \mathrm{c}$. This indicated that high value was mainly caused by faradic pseudocapacitance which was much higher than the double layer capacitance. Steep in high potential illustrated that capacitive behaviour was influenced by an electrical double layer structure accompanied by redox reaction, which arise from the electrochemical adsorption and released at the interface of the electrode and electrolyte [16,31]. From figure $7 d$, it could be clearly observed that $\mathrm{V}_{2} \mathrm{O}_{5}$ synthesized when the concentration of Mo-doped fractions was $2 \%$ displayed the highest specific capacitance. The specific capacitance of Modoped $\mathrm{V}_{2} \mathrm{O}_{5}$ nanomaterials prepared with concentrations of Mo fractions (0, 1, 2, 4 and 8\%) were, respectively, 453, 432, 526,443 and $278 \mathrm{~F} \mathrm{~g}^{-1}$, in agreement with the results of $\mathrm{CV}$. These results indicated that a moderate amount of Mo doping could improve energy storage capability of $\mathrm{V}_{2} \mathrm{O}_{5}$ nanomaterials. The reason may be that Mo doping transformed the 
(a)

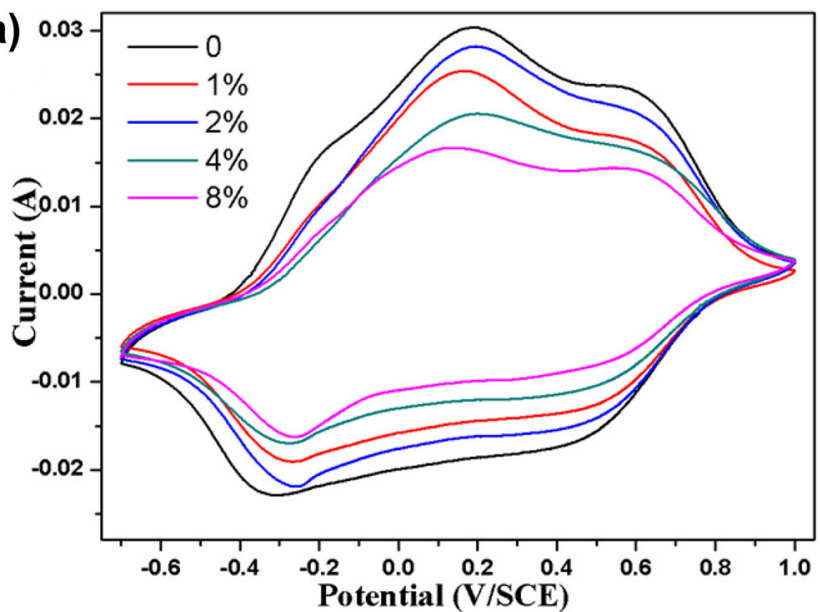

(c)

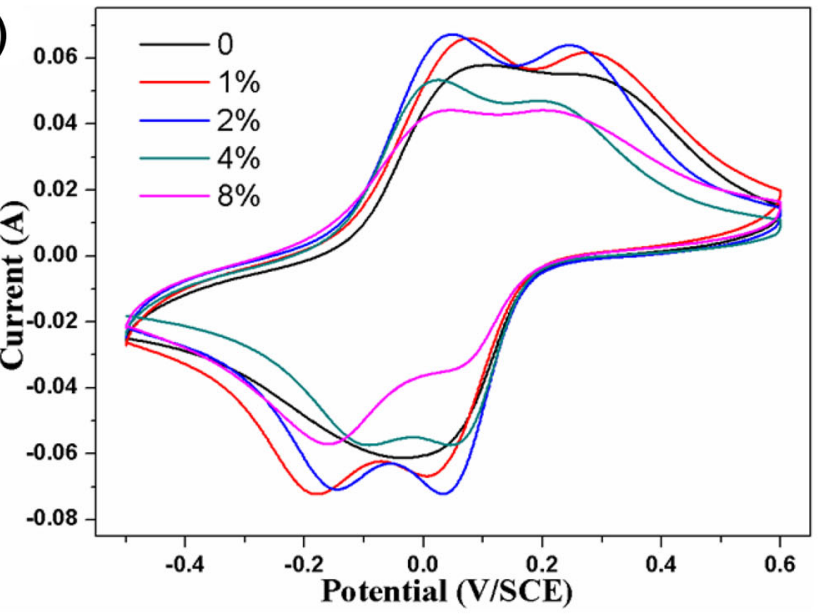

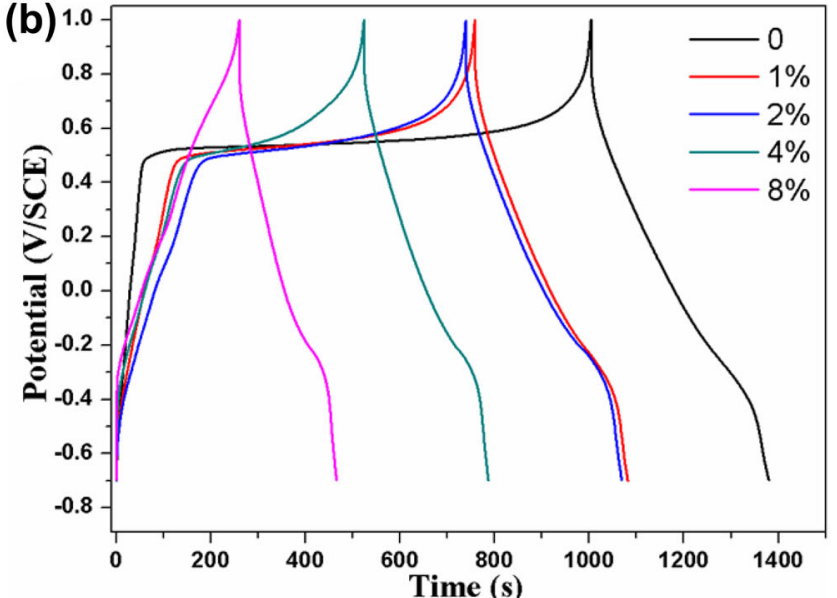

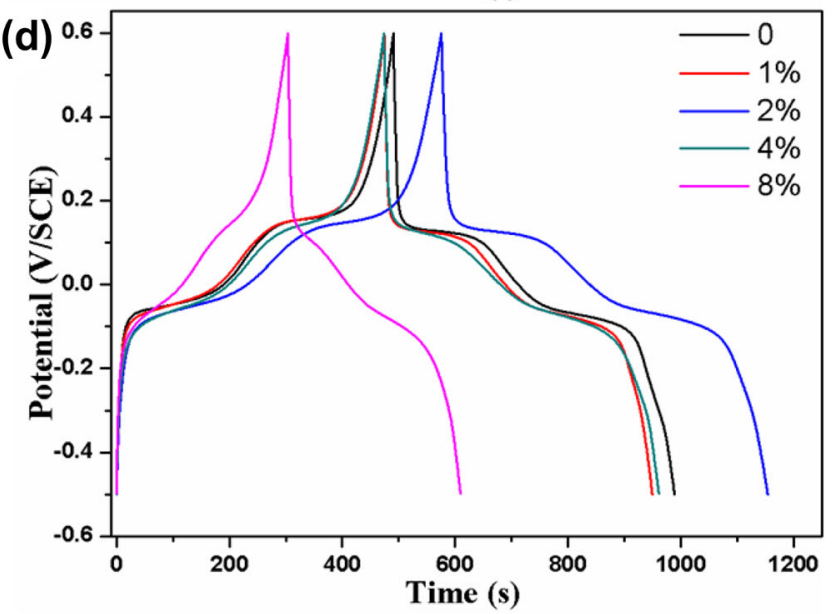

Figure 7. (a, c) $\mathrm{CV}$ curves at the scan rate of $10 \mathrm{mV} \mathrm{s}^{-1}$ and $(\mathbf{b}, \mathbf{d})$ potential $v s$. time for charge and discharge profiles at the current density of $1 \mathrm{~A} \mathrm{~g}^{-1}$ of Mo-doped $\mathrm{VO}_{x}$ nanobelts with different Mo-doped fractions: (a, b) Mo-doped $\mathrm{VO}_{2}(\mathrm{~B})$ nanobelts; (c, d) Mo-doped $\mathrm{V}_{2} \mathrm{O}_{5}$ nanobelts.

structure of $\mathrm{V}_{2} \mathrm{O}_{5}$ nanomaterials to an 'open-type', which increased utilization of the surface of $\mathrm{V}_{2} \mathrm{O}_{5}$ nanomaterials and accelerated the transfer of electrolyte ions. To disclose the reason for Mo-doped $\mathrm{V}_{2} \mathrm{O}_{5}$ exhibiting the best electrochemical behaviour, electrochemical impedance spectroscopy (EIS) was carried out over a frequency range of $100 \mathrm{kHz}-0.01 \mathrm{~Hz}$, as shown in figure 8 . The semicircle in the high-frequency region of the Nyquist plots represents the interfacial charge transfer resistance, which is mainly dependent on the conductivity of the electrode-electrolyte interface, the pore structure and the thickness of the active material [28]. The semicircle of Mo-doped $\mathrm{V}_{2} \mathrm{O}_{5}$ is smaller than that of pure $\mathrm{V}_{2} \mathrm{O}_{5}$, denoting an excellent interfacial charge-transfer behaviour. The equivalent series resistance including the electrolyte resistance, the intrinsic resistance of the active material, and the contact resistance between the active material and the current collector can be calculated from the intersection of the curve in the highfrequency region. These two samples show low equivalent series resistance, suggesting a good ion response in the highfrequency ranges and good connection between the active material and current collector [52].
According to the above analyses, 2\% Mo-doped $\mathrm{V}_{2} \mathrm{O}_{5}$ nanomaterials had the best electrochemical properties, thus, in the following we focused on this sample. Figure 9 displays the $\mathrm{CV}$ curves of Mo-doped $\mathrm{V}_{2} \mathrm{O}_{5}$ nanomaterials recorded at different scan rates from 2 to $100 \mathrm{mV} \mathrm{s}^{-1}$ within a potential window of -0.5 to $0.6 \mathrm{~V}$ in $1 \mathrm{moll}^{-1} \mathrm{LiNO}_{3}$ electrolyte. When the scan rate was under $20 \mathrm{mV} \mathrm{s}^{-1}$, each CV curve showed two pairs of redox peaks (two anodic peaks at positive current density and two cathodic peaks at negative current density), which indicated superior faradaic reactions at the electrode surface and the electrochemical redox reaction based on the $\mathrm{Li}$ ion intercalation and extraction was associated with the equation as follows [53]:

$$
\mathrm{V}_{2} \mathrm{O}_{5}+x \mathrm{Li}+x \mathrm{e}^{-} \underset{\text { charge }}{\stackrel{\text { discharge }}{\rightleftharpoons}} \mathrm{Li}_{x} \mathrm{~V}_{2} \mathrm{O}_{5} \quad(0 \leq x \leq 1)
$$

The changes of crystal phases occurred along with the whole process were generally designated as $\alpha(0<x<0.1), \varepsilon$ $(0.35<x<0.5)$ and $\delta(0.9<x<1)[34,53]$. When the scan rate was over $20 \mathrm{mV} \mathrm{s}^{-1}$, two pairs of redox peaks gradually 


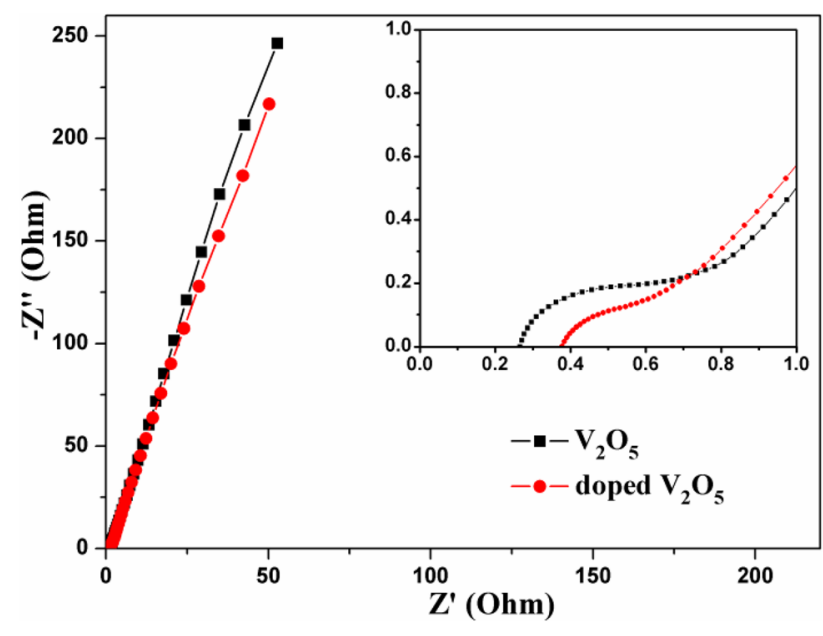

Figure 8. The comparable Nyquist plots of pure $\mathrm{V}_{2} \mathrm{O}_{5}$ and Modoped $\mathrm{V}_{2} \mathrm{O}_{5}$ nanomaterials obtained over the frequency range of $100 \mathrm{kHz}$ to $0.01 \mathrm{~Hz}$. overlapped with one pair of redox peaks. The response current of electrodes increased with the increase of the scan rate, which demonstrated excellent kinetics and reversibility of electrodes [16,31]. Furthermore, the oxidation peaks shifted positively and reduction peaks shifted negatively with the increasing of scan rates, which was attributed to the polarization effect of electrodes [16,31]. As depicted in figure 9, the redox peaks still existed even at $100 \mathrm{mV} \mathrm{s}^{-1}$ which indicated that Mo-doped $\mathrm{V}_{2} \mathrm{O}_{5}$ nanomaterials had good rate capability [19].

To quantify the rate capability of Mo-doped $\mathrm{V}_{2} \mathrm{O}_{5}$ nanomaterials, a GCD test was carried out. Figure 10 presents discharge curves performed at various current densities. The specific capacitances of the Mo-doped $\mathrm{V}_{2} \mathrm{O}_{5}$ nanomaterials calculated from the discharge time were 526, 464, 380, 324 and $273 \mathrm{~F} \mathrm{~g} \mathrm{~g}^{-1}$ at current densities of $1,2,5,10$ and $20 \mathrm{~A} \mathrm{~g}^{-1}$, respectively. With the increase of the current, the specific capacity declined. The gradual reduction of the
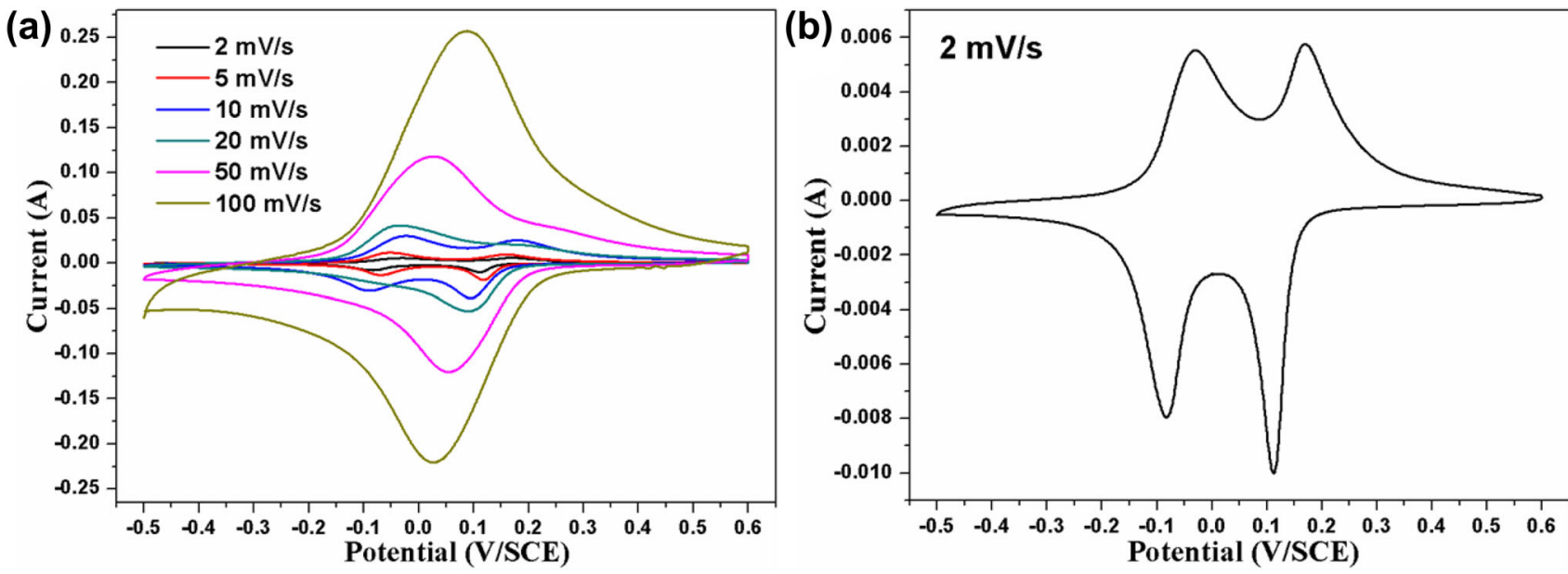

Figure 9. $\mathrm{CV}$ curves of Mo-doped $\mathrm{V}_{2} \mathrm{O}_{5}$ nanobelts at different scan rates.
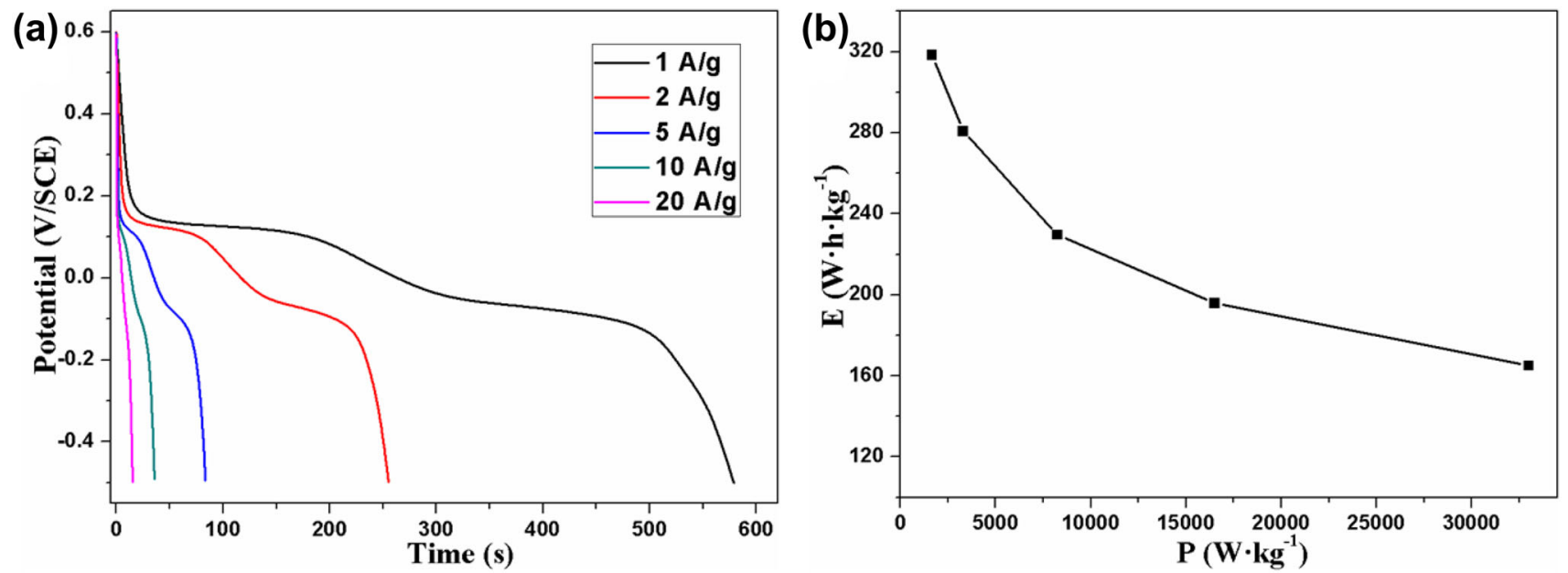

Figure 10. (a) Galvanostatic discharge curves at different current densities of Mo-doped $\mathrm{V}_{2} \mathrm{O}_{5}$ nanobelts and (b) Ragone plot of Modoped $\mathrm{V}_{2} \mathrm{O}_{5}$ nanobelts. 


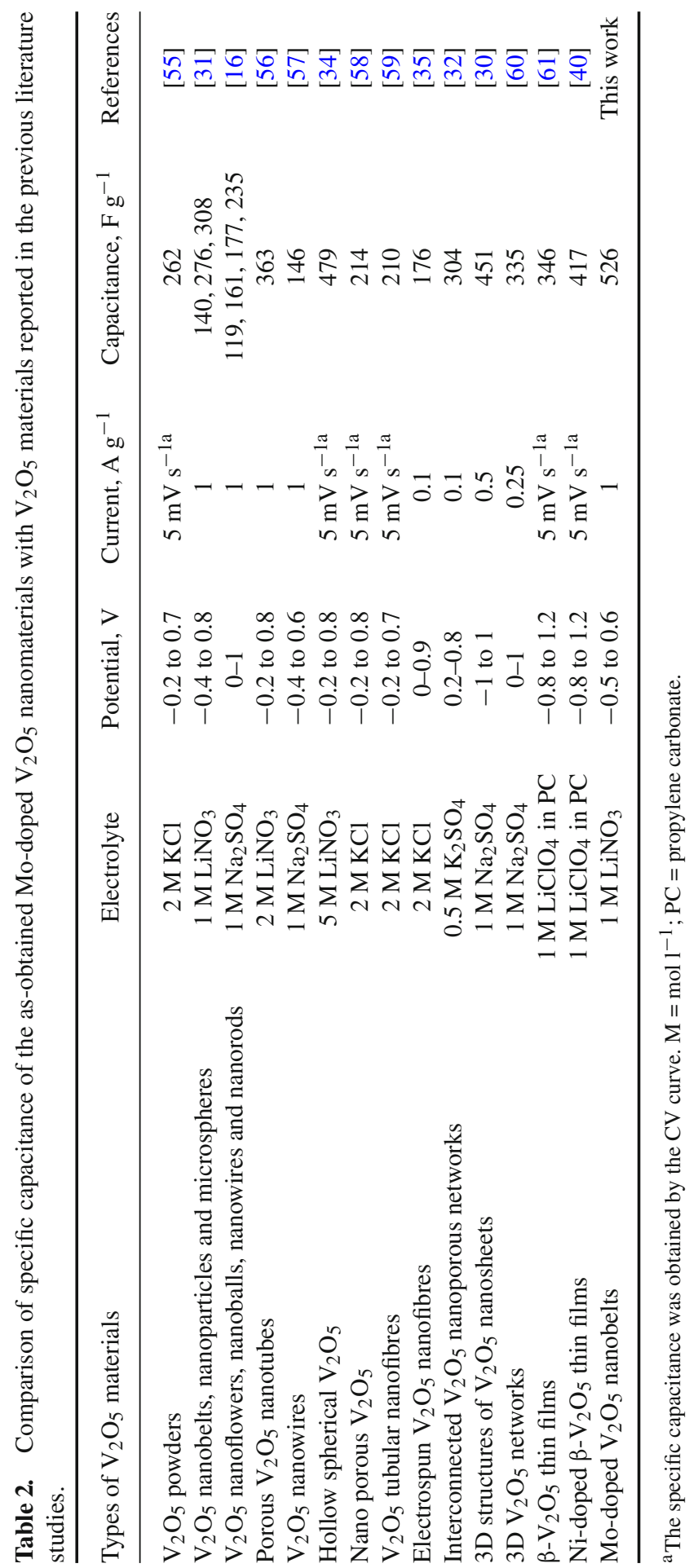


capacitance may be due to the incremental voltage drop and the insufficient active materials involved in the redox reactions at a higher current density [21,54]. Besides, the process of charge-discharge may lead to a low utilization rate of active materials at high-current density [1]. The attenuation of specific capacitance reduced slowly from the low-current density $\left(1 \mathrm{~A} \mathrm{~g} \mathrm{~g}^{-1}\right)$ to the high-current density $\left(20 \mathrm{~A} \mathrm{~g}^{-1}\right)$. The $88.2,72.2,61.6$ and $51.9 \%$ of the capacitance values at 2, 5, 10 and $20 \mathrm{~A} \mathrm{~g} \mathrm{~g}^{-1}$ could remain compared with the value at $1 \mathrm{~A} \mathrm{~g}^{-1}$. These results indicated that Mo-doped $\mathrm{V}_{2} \mathrm{O}_{5}$ nanomaterials had good rate capability in agreement with $\mathrm{CV}$ observations. In this contribution, we focused on the improvement of specific capacitance of $\mathrm{VO}_{x}$. Thus, it was necessary to compare the specific capacitance of Mo-doped $\mathrm{V}_{2} \mathrm{O}_{5}$ nanomaterials with other $\mathrm{V}_{2} \mathrm{O}_{5}$ materials of previous reports. Table 2 summarizes the values of specific capacitance of present Mo-doped $\mathrm{V}_{2} \mathrm{O}_{5}$ nanomaterials and other $\mathrm{V}_{2} \mathrm{O}_{5}$ materials reported in the previous literature. As can be seen, the specific capacitances of $\mathrm{V}_{2} \mathrm{O}_{5}$ nanomaterials are much higher than the previous values of $\mathrm{V}_{2} \mathrm{O}_{5}$ materials in the aqueous electrolyte. Furthermore, Mo-doped $\mathrm{V}_{2} \mathrm{O}_{5}$ nanomaterials (526 $\mathrm{F} \mathrm{g}^{-1}$ ) had higher specific capacitance than Ni-doped $\beta-\mathrm{V}_{2} \mathrm{O}_{5}$ thin films $\left(417 \mathrm{~F} \mathrm{~g}^{-1}\right.$ ) as reported by Jeyalakshmi et al [40]. Figure $8 \mathrm{~b}$ shows the Ragone plot of the as-prepared Mo-doped $\mathrm{V}_{2} \mathrm{O}_{5}$ nanomaterials. According to equations (3) and (4), the calculated $E$ values at current densities of $1,2,5,10$ and $20 \mathrm{~A} \mathrm{~g} \mathrm{~g}^{-1}$ were 318, 281, 230, 196 and $165 \mathrm{~W} \mathrm{~h} \mathrm{~kg}^{-1}$, respectively, and the corresponding $P$ values were 1980, 3960, 9900, 19,800 and 39,600 $\mathrm{W} \mathrm{kg}^{-1}$, respectively, which exhibited outstanding electrochemical performance of Mo-doped $\mathrm{V}_{2} \mathrm{O}_{5}$ nanomaterials. Therefore, nano-structured Mo-doped $\mathrm{V}_{2} \mathrm{O}_{5}$ prepared in this study using a simple chemical route exhibited an excellent capacity and was considered to be one of the most promising candidates for SC electrodes in the future.

\section{Conclusion}

In summary, Mo-doped $\mathrm{VO}_{2}(\mathrm{~B})$ and Mo-doped $\mathrm{V}_{2} \mathrm{O}_{5}$ nanomaterials were successfully synthesized using commercial $\mathrm{V}_{2} \mathrm{O}_{5}$ as the starting material and ammonium molybdate as the dopant. The samples were characterized by XRD, EDS, elemental mapping, XPS, XRF and TEM techniques. The results showed that $\mathrm{Mo-doped} \mathrm{VO}_{2}(\mathrm{~B})$ and $\mathrm{V}_{2} \mathrm{O}_{5}$ solid solutions with high purity were obtained. The electrochemical properties of Mo-doped $\mathrm{VO}_{2}(\mathrm{~B})$ and $\mathrm{V}_{2} \mathrm{O}_{5}$ nanomaterials as $\mathrm{SC}$ electrodes were measured using $\mathrm{CV}$ and GCD. Specific capacitance of $\mathrm{VO}_{2}(\mathrm{~B})$ nanomaterials slightly declined by Mo doping, however, specific capacitance of $\mathrm{V}_{2} \mathrm{O}_{5}$ nanomaterials greatly improved by Mo doping. Mo-doped $\mathrm{V}_{2} \mathrm{O}_{5}$ nanomaterials exhibited specific capacitance as high as $526 \mathrm{~F} \mathrm{~g}^{-1}$ at the current density of $1 \mathrm{~A} \mathrm{~g}^{-1}$, and they had good rate capability. Mo-doped $\mathrm{V}_{2} \mathrm{O}_{5}$ nanomaterials retained specific capacitances of 464, 380, 324 and $273 \mathrm{~F} \mathrm{~g} \mathrm{~g}^{-1}$ even at high-current densities of $2,5,10$ and $20 \mathrm{~A} \mathrm{~g}^{-1}$, respectively. The significance of this work was that it provided more insights into the influence of Mo doping on the electrochemical properties of $\mathrm{VO}_{x}$.

\section{Acknowledgements}

This work was partially supported by the National Natural Science Foundation of China (Grant Nos. 21601026 and 21771030) and Doctoral Research Foundation of Liaoning Province (201601035).

\section{References}

[1] Yu Z, Tetard L, Zhai L and Thomas J 2015 Energy Environ. Sci. 8702

[2] Zhong C, Deng Y, Hu W, Qiao J, Zhang L and Zhang J 2015 Chem. Soc. Rev. 447484

[3] Zhang Y and Meng C 2015 Mater. Lett. 160404

[4] Yu M, Qiu W, Wang F, Zhai T, Fang P, Lu X et al 2015 J. Mater. Chem. A 315792

[5] Zhang Y, Zheng J, Wang Q, Hu T and Meng C 2016 RSC Adv. 6 93741

[6] Jing X, Wang C, Feng W, Xing N, Jiang H, Lu X et al 2018 R. Soc. Open Sci. 5171768

[7] Zhang Y 2018 Chem. Sel. 31577

[8] Xia X, Zhang Y, Chao D, Guan C, Zhang Y, Li L et al 2014 Nanoscale 65008

[9] Zhang L L and Zhao X S 2009 Chem. Soc. Rev. 382520

[10] Zheng J, Zhang Y, Wang N, Zhao Y, Tian F and Meng C 2016 Mater. Lett. 171240

[11] Singh A and Chandra A 2015 Sci. Rep. 515551

[12] Trasatti S and Kurzweil I 1994 Platinum Met. Rev. 3846

[13] Perera S D, Rudolph M, Mariano R G, Nijem N, Ferraris J P, Chabal Y J et al 2013 Nano Energy 2966

[14] Wang Q, Zhang Y, Zheng J, Wang Y, Hu T and Meng C 2017 Dalton Trans. 464303

[15] Umeshbabu E and Ranga Rao G 2016 J. Colloid Interface Sci. 472210

[16] Mu J, Wang J, Hao J, Cao P, Zhao S, Zeng W et al 2015 Ceram. Int. 4112626

[17] Peng T, Wang J, Liu Q, Liu J and Wang P 2015 CrystEngComm 171673

[18] Guo Y, Li J, Chen M and Gao G 2015 J. Power Sources 273 804

[19] Wang N, Zhang Y, Hu T, Zhao Y and Meng C 2015 Curr. Appl. Phys. 15493

[20] Zhang Y and Huang Y 2016 Mater. Lett. 182285

[21] Liang L, Liu H and Yang W 2013 J. Alloys Compd. 559167

[22] Xu L, Zhang Y, Deng Y, Zhong Y, Mo S, Cheng G et al 2013 Mater. Res. Bull. 483620

[23] Zhang Y, Huang Y, Zhang J, Wu W, Niu F, Zhong Y et al 2012 Mater. Res. Bull. 471978

[24] Zhang Y, Fan M, Zhou M, Huang C, Chen C, Cao Y et al 2012 Bull. Mater. Sci. 35369

[25] Xu L, Zhang Y, Zhang X, Huang Y, Tan X, Huang C et al 2014 Bull. Mater. Sci. 371397

[26] Zhang Y, Zheng J, Wang Q, Zhang S, Hu T and Meng C 2017 Appl. Surf. Sci. $\mathbf{4 2 3} 728$ 
[27] Zhang Y, Jing X, Wang Q, Zheng J, Jiang H and Meng C 2017 Dalton Trans. 4615048

[28] Zheng J, Zhang Y, Wang Q, Jiang H, Liu Y, Lv T et al 2018 Dalton Trans. 47452

[29] Hu T, Liu Y, Zhang Y, Nie Y, Zheng J, Wang Q et al 2018 Microporous Mesoporous Mater. 262199

[30] Zhu J, Cao L, Wu Y, Gong Y, Liu Z, Hoster H E et al 2013 Nano Lett. 135408

[31] Zhang Y, Zheng J, Zhao Y, Hu T, Gao Z and Meng C 2016 Appl. Surf. Sci. 377385

[32] Saravanakumar B, Purushothaman K K and Muralidharan G 2012 ACS Appl. Mater. Interfaces 44484

[33] Zhang Y, Zheng J, Hu T, Tian F and Meng C 2016 Appl. Surf. Sci. 371189

[34] Yang J, Lan T, Liu J, Song Y and Wei M 2013 Electrochim. Acta $\mathbf{1 0 5} 489$

[35] Wee G, Soh H Z, Cheah Y L, Mhaisalkar S G and Srinivasan M 2010 J. Mater. Chem. 206720

[36] Zhang Y, Zheng J, Wang Q, Hu T, Tian F and Meng C 2017 Appl. Surf. Sci. 399151

[37] Zhi M, Xiang C, Li J, Li M and Wu N 2013 Nanoscale 572

[38] Qian T, Xu N, Zhou J, Yang T, Liu X, Shen X et al 2015 J. Mater. Chem. A 3488

[39] Wu Y, Gao G and Wu G 2015 J. Mater. Chem. A 31828

[40] Jeyalakshmi K, Vijayakumar S, Purushothaman K K and Muralidharan G 2013 Mater. Res. Bull. 482578

[41] Zheng J, Zhang Y, Jing X, Wang Q, Hu T, Xing N et al 2017 Mater. Chem. Phys. 1665

[42] Zhang Y, Chen C, Wu W, Niu F, Liu X, Zhong Y et al 2013 Ceram. Int. 39129

[43] Theobald F, Cabala R and Bernard J 1976 J. Solid State Chem. 17431

[44] Zhang Y, Li W, Fan M, Zhang F, Zhang J, Liu X et al 2012 J. Alloys Compd. $\mathbf{5 4 4} 30$
[45] Enjalbert R and Galy J 1986 Acta Crystallogr. C 421467

[46] Zhang Y, Zhang J, Zhang X, Mo S, Wu W, Niu F et al 2013 J. Alloys Compd. $\mathbf{5 7 0} 104$

[47] Silversmit G, Depla D, Poelman H, Marin G B and Gryse R D 2004 J. Electron Spectrosc. 135167

[48] Wagner C D, Riggs W M, Davis L E and Moulder J F 1979 Handbook of X-ray photoelectrom spectroscopy (Minnesota: Perkin-Elmer Corporation)

[49] Tang C, Georgopoulos P, Fine M E, Cohen J B, Nygren M, Knapp G S et al 1985 Phys. Rev. B 311000

[50] Manning T D, Parkin I P, Blackman C and Qureshi U $2005 \mathrm{~J}$. Mater. Chem. 154560

[51] Zhang Y, Zhang J, Zhang X, Deng Y, Zhong Y, Huang C et al 2013 Ceram. Int. 398363

[52] Qi J L, Wang X, Lin J H, Zhang F, Feng J C and Fei W D 2015 J. Mater. Chem. A 312396

[53] Delmas C, Cognac-Auradou H, Cocciantelli J M, Menetrier M and Doumerc J P 1994 Solid State Ion. 69257

[54] Deng L, Zhang G, Kang L, Lei Z, Liu C and Liu Z-H 2013 Electrochim. Acta 112448

[55] Lao Z J, Konstantinov K, Tournaire Y, Ng S H, Wang G X and Liu H K 2006 J. Power Sources 1621451

[56] Lin Z, Yan X, Lang J, Wang R and Kong L-B 2015 J. Power Sources 279358

[57] Chen Z, Qin Y, Weng D, Xiao Q, Peng Y, Wang X et al 2009 Adv. Funct. Mater. 193420

[58] Reddy R N and Reddy R G 2006 J. Power Sources 156 700

[59] Lala N L, Jose R, Yusoff M M and Ramakrishna S $2012 \mathrm{~J}$. Nanopart. Res. 141201

[60] Cao L, Zhu J, Li Y, Xiao P, Zhang Y, Zhang S et al 2014 J. Mater. Chem. A 213136

[61] Jeyalakshmi K, Vijayakumar S, Nagamuthu S and Muralidharan G 2013 Mater. Res. Bull. 48760 